\title{
A Low Power Voltage Controlled Oscillator Design
}

\author{
Manoj Kumar \\ Department of Electronics \& Communication Engineering, Guru Jambheshwar University of Science \& Technology, Hisar 125001, India
}

Correspondence should be addressed to Manoj Kumar; manojtaleja@gjust.org

Received 5 April 2013; Accepted 25 April 2013

Academic Editors: S. Hall, R. Luzzi, V. McGahay, P. Wachulak, and X. Yang

Copyright (C) 2013 Manoj Kumar. This is an open access article distributed under the Creative Commons Attribution License, which permits unrestricted use, distribution, and reproduction in any medium, provided the original work is properly cited.

\begin{abstract}
The performance of voltage controlled oscillator (VCO) is of great importance for any telecommunication or data transmission network. Here, voltage controlled oscillators (VCOs) using three-transistor NAND gates have been designed. New delay cell with three-transistor NAND gate has been used for designing the ring based VCO circuits. Three-, five-, and seven-stage VCOs have been proposed. Output frequency has been controlled with supply voltage variation from $1.8 \mathrm{~V}$ to $2.4 \mathrm{~V}$. Three stage VCO shows output frequency variation in the range of $3.2909 \mathrm{GHz}$ to $4.2280 \mathrm{GHz}$ whereas power consumption varies in the range of $335.4071 \mu \mathrm{W}$ to $486.1816 \mu \mathrm{W}$. Five-stage VCO depicts frequency in the range of $1.9406 \mathrm{GHz}$ to $2.5769 \mathrm{GHz}$ with power consumption variation from $559.0118 \mu \mathrm{W}$ to $810.3027 \mu \mathrm{W}$. Moreover a seven-stage VCO shows frequency variation from $1.3984 \mathrm{GHz}$ to $1.8077 \mathrm{GHz}$. Power consumption of seven-stage VCO varies from $782.6165 \mu \mathrm{W}$ to $1134.400 \mu \mathrm{W}$. Phase noise results for these VCOs have also been obtained. Power consumption, output frequency, and phase noise results of proposed circuits have been compared with earlier reported circuits, and the proposed circuits show significant improvements.
\end{abstract}

\section{Introduction}

Oscillators are the most fundamental blocks in various communication systems. With each generation of communication and microprocessor technology data rates are increasing at a very fast pace. In modern high performance systems phase-locked loops (PLLs) are the commonly used circuit component with wide application in frequency synthesis, clock, and data recovery [1-3]. PLL block contains a phase detector, a charge pump, a loop filter, and voltage controlled oscillator circuit. VCO is the major part of PLL circuit and it affects the system performance in terms of power consumption and noise performance. In modern VCO designs power consumption and high output frequency range have become important performance metrics. Two widely used VCO types are LC tank and CMOS ring based circuits. Combination of capacitor and inductor on integrated circuits consumes large layout area in LC tank based VCO designs [4-6]. CMOS ring based oscillators show advantages due to ease of controlling the output frequency and nonrequirement for on chip inductors $[7,8]$. With the beginning of very large scale integration (VLSI) technology CMOS based VCOs are more accepted in PLL systems. These are also easier to integrate and provide wide tuning range. Further, with the rising demand of portable devices like cellular phones, notebooks, and personal communication devices, the need for power saving has also increased many times. Power consumption in very large scale integration (VLSI) systems includes dynamic, static power and leakage power consumption. Total power consumption in any CMOS circuit is given as

$$
P_{\text {total }}=\alpha C_{L} V_{d d}^{2} f+I_{\text {sc }} V_{d d}+I_{\text {sub }} V_{d d}+I_{\text {gateleakage }} V_{d d},
$$

$\alpha$ is the switching activity, $C_{L}$ is the capacitance of the load, $f$ is the clock frequency, and $V_{d d}$ is the supply voltage. $I_{\mathrm{sc}}$ is the short circuit current, which flows directly from the power supply to ground terminal when NMOS subnetwork and PMOS subnetwork conduct simultaneously. $I_{\text {sub }}$ is the leakage current which results from substrate injection and subthreshold effects. The reverse biased $p$ - $n$ junction current is the static dissipation due to reverse biased diode leakage between the diffusion regions, wells, and substrate. $I_{\text {gateleakage }}$ is the gate leakage current which arises from gate oxide which is mostly dependant on gate oxide thickness. The first two components in (1) represent the dynamic power consumption and the remaining two components show static power consumption. In ring based oscillator design output of last stage is fed back to input of first stage. A VCO block diagram with single ended $\mathrm{N}$-delay inverter stages is shown in Figure 1. 
TABLE 1: Results for NAND delay based VCOs.

\begin{tabular}{|c|c|c|c|c|c|c|}
\hline \multirow[b]{2}{*}{$\begin{array}{l}\text { Control voltage } \\
\text { (V) }\end{array}$} & \multicolumn{2}{|c|}{ Three-stage VCO } & \multicolumn{2}{|c|}{ Five-stage VCO } & \multicolumn{2}{|c|}{ Seven-stage VCO } \\
\hline & $\begin{array}{c}\text { Output } \\
\text { frequency } \\
(\mathrm{GHz})\end{array}$ & $\begin{array}{c}\text { Power } \\
\text { consumption } \\
(\mu \mathrm{W})\end{array}$ & $\begin{array}{c}\text { Output } \\
\text { frequency } \\
(\mathrm{GHz})\end{array}$ & $\begin{array}{c}\text { Power } \\
\text { consumption } \\
(\mu \mathrm{W})\end{array}$ & $\begin{array}{c}\text { Output } \\
\text { frequency } \\
(\mathrm{GHz})\end{array}$ & $\begin{array}{c}\text { Power } \\
\text { consumption } \\
(\mu \mathrm{W})\end{array}$ \\
\hline 1.8 & 3.2909 & 335.4071 & 1.9406 & 559.0118 & 1.3984 & 782.6165 \\
\hline 1.9 & 3.3964 & 359.4469 & 2.0288 & 599.0782 & 1.4401 & 838.7095 \\
\hline 2.0 & 3.5444 & 383.8849 & 2.0959 & 639.8081 & 1.5010 & 895.7314 \\
\hline 2.1 & 3.7092 & 408.7571 & 2.2106 & 681.2619 & 1.5954 & 953.7666 \\
\hline 2.2 & 3.9342 & 434.0872 & 2.3065 & 723.4787 & 1.6432 & 1012.900 \\
\hline 2.3 & 4.1088 & 459.8914 & 2.3716 & 766.4857 & 1.7290 & 1073.100 \\
\hline 2.4 & 4.2280 & 486.1816 & 2.5769 & 810.3027 & 1.8077 & 1134.400 \\
\hline
\end{tabular}

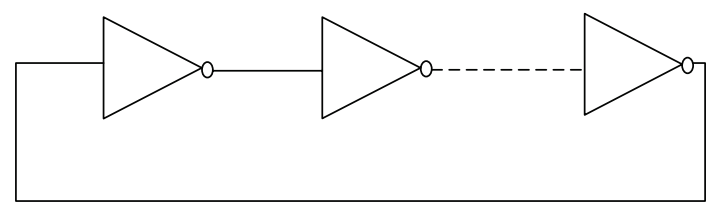

Figure 1: Single ended VCO.

The ring structure must provide a phase shift of $2 \pi$ and unity voltage gain for oscillation occurrence. Each delay cell should provide a phase shift of $\pi / N$, where $N$ is the total number of delay stages. The remaining $\pi$ phase shift is provided by dc inversion of the inverter delay cells. In single ended oscillator designs the odd numbers of delay stages are required for dc inversion. Frequency of oscillation of VCO designed with $N$-single ended delay stages is given by $f_{o}=$ $1 / 2 N t_{d}$, where $N$ is the total number of delay stages and $t_{d}$ is delay of each stage $[9,10]$. Different types of delay cells have been reported in the literature for oscillator design including multiple-feedback loops, dual-delay paths, and single ended delays [11-20]. Delay cells have been implemented by different approaches like inverter stages, latches, cross-coupled cells and so forth. Delay stages are the fundamental building blocks in any VCO design and improved design of these delay cells affects the overall performance of VCO design. In the present work a new delay cell has been designed considering the importance of power consumption and frequency range.

The paper is organized as follows: in Section 2, a threetransistor NAND gate has been discussed. Further, three-, five-, and seven-stage VCOs have been designed with NAND delay cell. In Section 3 results of proposed circuits have been described and compared with the earlier circuits. Finally conclusions have been presented in Section 4 .

\section{Circuit Description}

The output frequency of ring VCO depends on the delay provided by each inverter delay cell. In the proposed designs delay cells based on three-transistor NAND gates are used. Inverter operation has been obtained by three-transistor NAND gate as shown in Figure 2. The circuits have been designed in $0.18 \mu \mathrm{m}$ CMOS technology with supply voltage of $1.8 \mathrm{~V}$. Supply voltage/control voltage has been varied from $1.8 \mathrm{~V}$ to $2.4 \mathrm{~V}$ to obtain the different output frequency

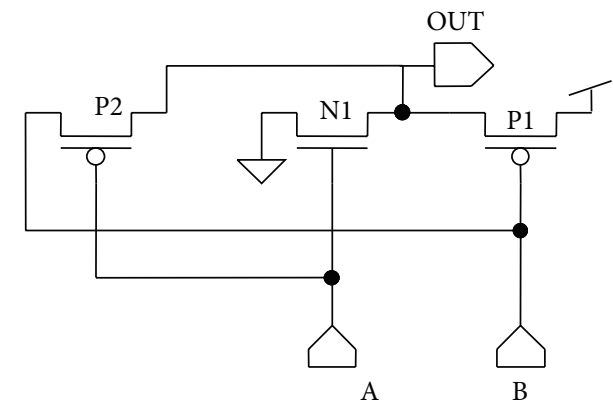

FIgURE 2: Three-transistor NAND gate.

components. Direct path between $V_{d d}$ and ground has been eliminated in the delay cells, due to which leakage power is reduced and the designs are power efficient.

NAND delay stage is made up of two PMOS transistors and one NMOS transistor. Out of two input terminals of NAND gate, one is connected to logic 1 (i.e., 1.0 V) and feedback signal is applied to the other terminal. This circuits works as inverter without having direct path between $V_{d d}$ and ground with saving in power consumption. The gate lengths of all three transistors have been taken as $0.18 \mu \mathrm{m}$. Width $\left(W_{n}\right)$ of NMOS transistor (N1) has been taken as $0.25 \mu \mathrm{m}$. Width $\left(W_{p}\right)$ of transistors $\mathrm{P} 1$ and $\mathrm{P} 2$ has been taken as $1.25 \mu \mathrm{m}$. Output frequency has been controlled by varying the supply voltage $\left(V_{d d}\right)$ of NAND delay stages. Three- and five-stage VCOs have been shown in Figures 3(a) and 3(b). Seven-stage VCOs have also been designed with the same concept.

The proposed NAND gate has only three transistors so the design is more power efficient and requires less area as compared to conventional four-transistor NAND or NOR gates. The proposed NAND gate design is based on pass transistor logic which has reduced internal capacitance and is suitable for power efficient circuits [15]. In NAND gate design direct connection to $V_{d d}$ is eliminated and there is only one NMOS transistor connected to ground so the design is power efficient as compared to that implemented with conventional gates.

\section{Results and Discussions}

Simulations have been carried out using SPICE based on TSMC $0.18 \mu \mathrm{m}$ technology with supply voltage variations from $1.8 \mathrm{~V}$ to $2.4 \mathrm{~V}$. Table 1 shows the results of power 


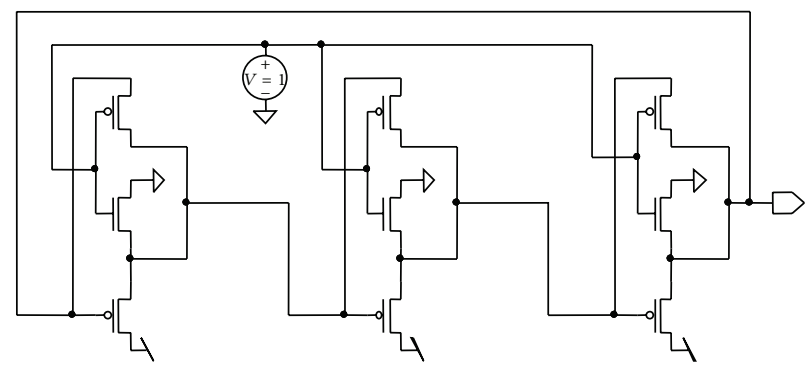

(a)

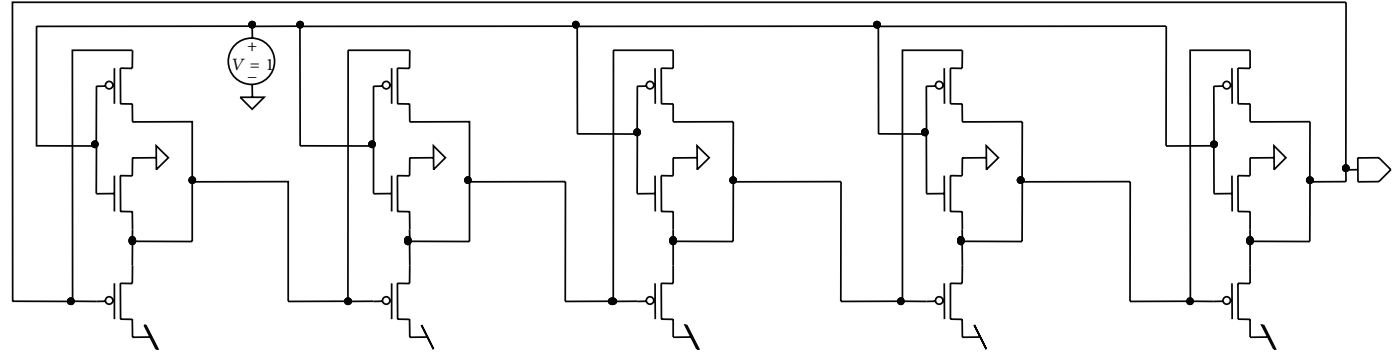

(b)

Figure 3: (a) Three-stage VCOs (b) Five-stage VCO.

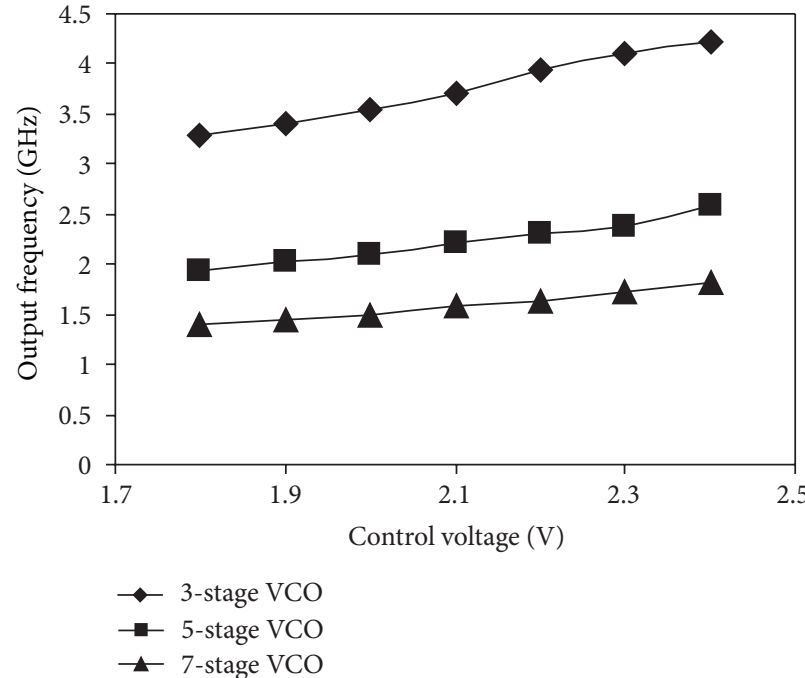

(a)

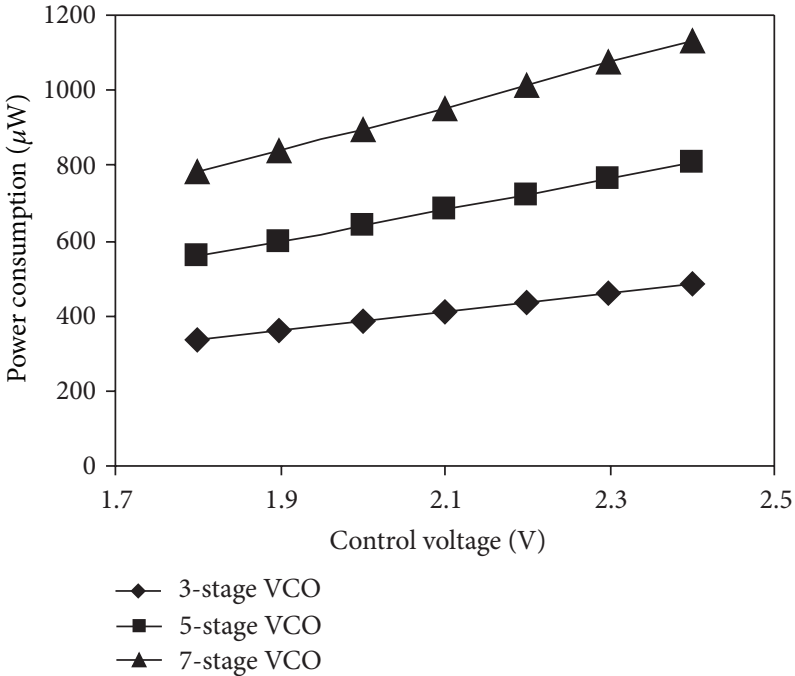

(b)

FIGURE 4: (a) Frequency and (b) power consumption variations of three-, five-, and seven-stage VCOs.

consumption and output frequency for three-, five-, and seven-stage VCOs.

Output frequency of three-stage VCO shows variation from $3.2909 \mathrm{GHz}$ to $4.2280 \mathrm{GHz}$ with power consumption variation from $335.4071 \mu \mathrm{W}$ to $486.1816 \mu \mathrm{W}$. In five-stage ring VCO frequency varies from $1.9406 \mathrm{GHz}$ to $2.5769 \mathrm{GHz}$ with power consumption variation from $559.0118 \mu \mathrm{W}$ to $810.3027 \mu \mathrm{W}$. Finally, in seven-stage ring VCO frequency varies from $1.3984 \mathrm{GHz}$ to $1.8077 \mathrm{GHz}$ with power consumption variation from $782.6165 \mu \mathrm{W}$ to $1134.400 \mu \mathrm{W}$. Figures $4(\mathrm{a})$ and $4(\mathrm{~b})$ show frequency and power consumption variation for three-, five-, and seven-stage VCOs. Figure 5 shows
TABLE 2

\begin{tabular}{lcc}
\hline VCO circuit & Phase noise $(\mathrm{dBc} / \mathrm{Hz})$ & Control voltage \\
\hline 3-stage NAND VCO & -80.9461 at $1 \mathrm{MHz}$ & $1.8 \mathrm{~V}$ \\
5-stage NAND VCO & -84.5595 at $1 \mathrm{MHz}$ & $1.8 \mathrm{~V}$ \\
7-stage NAND VCO & -86.6507 at $1 \mathrm{MHz}$ & $1.8 \mathrm{~V}$ \\
\hline
\end{tabular}

output waveforms for three-, five-, and seven-stage NAND VCOs at supply voltage of $1.8 \mathrm{~V}$.

Table 2 shows results of phase noise performance for three-, five-, and seven-stage ring VCOs designed with 
TABLE 3: Comparison of VCO performances.

\begin{tabular}{|c|c|c|c|c|c|}
\hline VCO designs & $\begin{array}{c}\text { Operating } \\
\text { frequency } \\
(\mathrm{GHz})\end{array}$ & $\begin{array}{r}\text { VDD } \\
(\mathrm{V})\end{array}$ & $\begin{array}{l}\text { Technology } \\
(\mu \mathrm{m})\end{array}$ & Power consumption & $\begin{array}{l}\text { Phase noise } \\
\qquad(\mathrm{dBc} / \mathrm{Hz})\end{array}$ \\
\hline [4] & $2.17-2.73$ & 0.9 & 0.18 & $2.7 \mathrm{~mW}$ & -122.3 at $1 \mathrm{MHz}$ \\
\hline$[8]$ & $0.39-1.41$ & 1.8 & 0.18 & $12.5 \mathrm{~mW}$ & -80 at $600 \mathrm{KHz}$ \\
\hline [11] & $0.12-1.3$ & 0.5 & 0.18 & $0.085 \mathrm{~mW}$ & - \\
\hline$[14]$ & $1.57-3.57$ & 1.8 & 0.090 & $16.8 \mathrm{~mW}$ & -90.01 at $600 \mathrm{kHz}$ \\
\hline$[16]$ & $0.65-1.6$ & 1.8 & 0.18 & $39 \mathrm{~mW}$ & -108 at $0.2 \mathrm{MHz}$ \\
\hline Present work 3 stages & $3.2909-4.2280$ & 1.8 & 0.18 & $335.4071-486.1816 \mu \mathrm{W}$ & -80.9461 at $1 \mathrm{MHz}$ \\
\hline Present work 5 stages & $1.9406-2.5769$ & 1.8 & 0.18 & $559.0118-810.3027 \mu \mathrm{W}$ & -84.5595 at $1 \mathrm{MHz}$ \\
\hline Present work 7 stages & $1.3984-1.8077$ & 1.8 & 0.18 & $782.6165-1134.400 \mu \mathrm{W}$ & -86.6507 at $1 \mathrm{MHz}$ \\
\hline
\end{tabular}

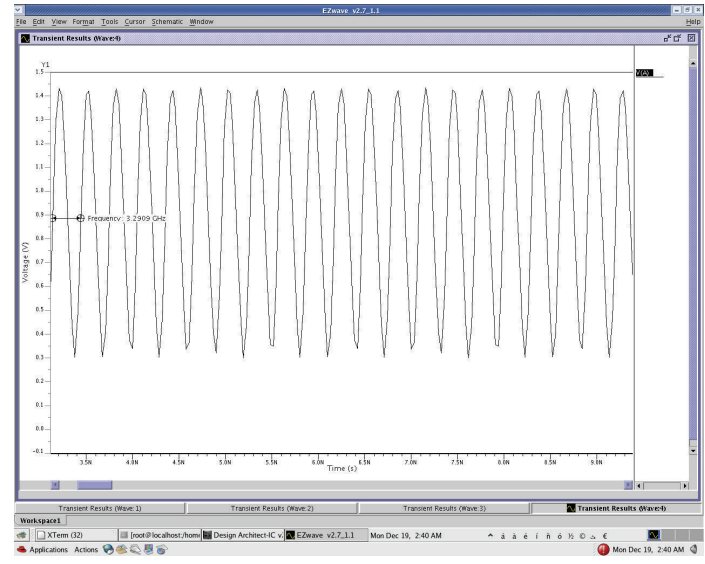

(a)

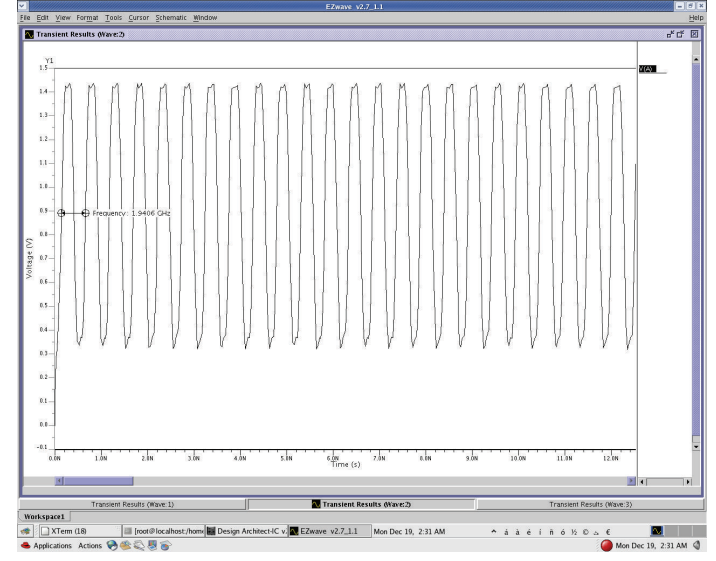

(b)

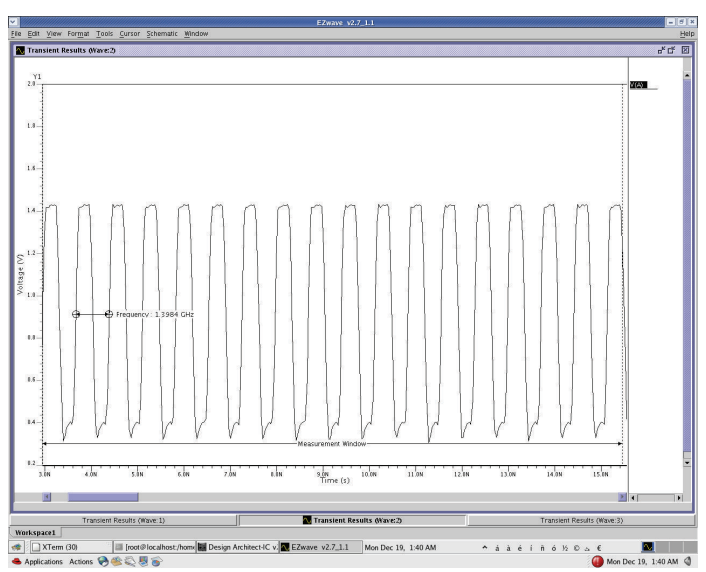

(c)

FIGURE 5: Output waveforms: (a) 3-stage VCO, (b) 5-stage VCO and (c) 7-stage VCO.

NAND delay cells. Figures 6(a), 6(b), and 6(c) shows phase noise at $1 \mathrm{MHz}$ offset for three-, five-, and seven-stage VCOs.

In the reported circuits, power consumption is showing upward trend with increase in number of delay stages whereas output frequency is showing downward trend. The number of stages may be decreased or increased depending upon the application and requirement for output frequency range. A comparison with earlier reported circuits in terms of power consumption and output frequency range is given in Table 3.
The proposed circuits show superior performance in terms of power consumption and output frequency range than the compared circuits.

\section{Conclusions}

In the reported work CMOS ring VCO designs have been improved with three-transistor NAND gates. Three-, fiveand seven-stage VCOs have been reported with reduced 


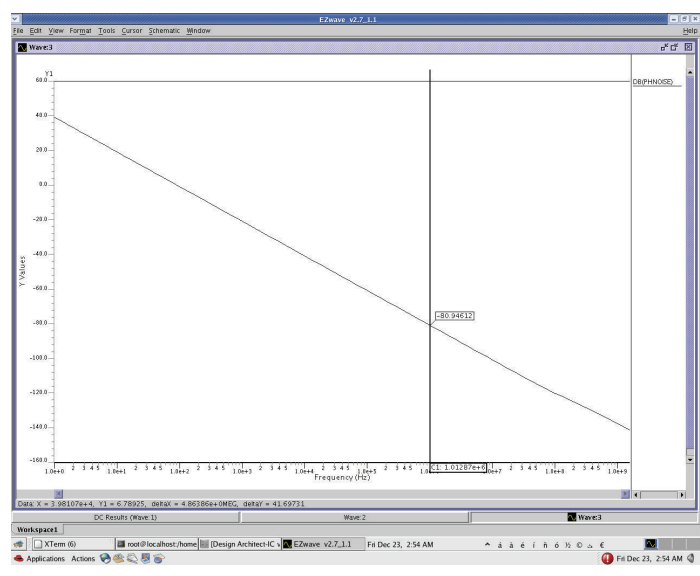

(a)

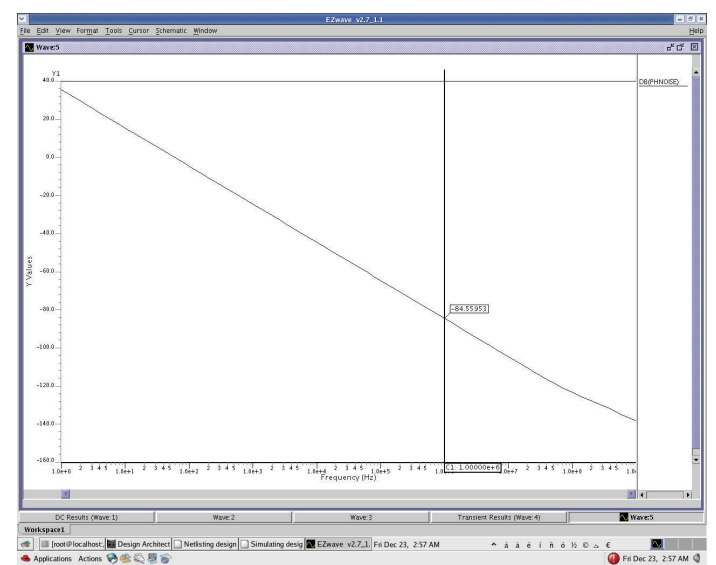

(b)

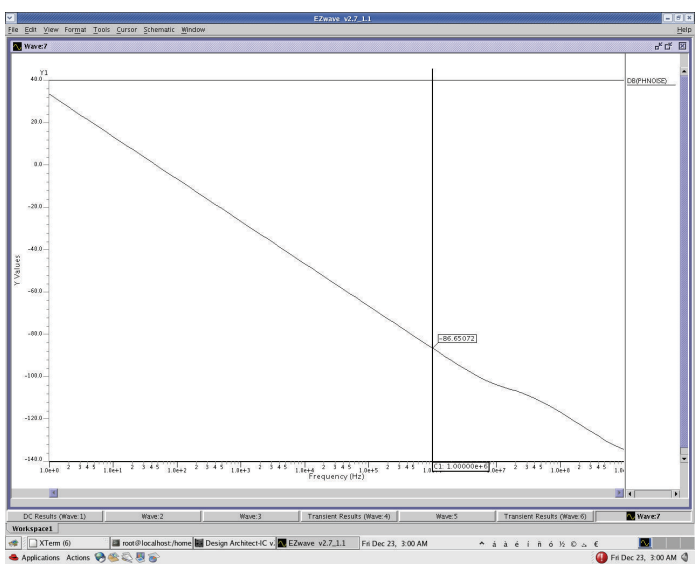

(c)

FIgure 6: Phase noise for (a) 3-stage VCO, (b) 5-stage VCO, and (c) 7-stage VCO.

power consumption. Three-stage VCO shows frequency variation in the range of $3.2909 \mathrm{GHz}$ to $4.2280 \mathrm{GHz}$. Five-stage NAND delay based VCO provides output frequency from $1.9406 \mathrm{GHz}$ to $2.5769 \mathrm{GHz}$. Finally the VCO designed with seven-stage NAND delay cells depicts frequency variation from $1.3984 \mathrm{GHz}$ to $1.8077 \mathrm{GHz}$. Phase noise performances of proposed circuits also show good agreement with earlier circuits. Three- and five-stage VCOs show phase noise of $-80.9461 \mathrm{dBc} / \mathrm{Hz}$ and $-84.5595 \mathrm{dBc} / \mathrm{Hz}$, respectively with the offset of $1 \mathrm{MHz}$. Finally the seven-stage VCO shows phase noise of $-86.6507 \mathrm{dBc} / \mathrm{Hz}$. The proposed designs have been compared with the previously reported design and our approach shows significant power saving with wide tuning range.

\section{References}

[1] T. Y. Hsu, C. C. Wang, and C. Y. Lee, "Design and analysis of a portable high-speed clock generator," IEEE Transaction Circuits System II, vol. 48, pp. 367-375, 2001.

[2] D. W. Boerstler, "Low-jitter PLL clock generator for microprocessors with lock range of 340-612 MHz," IEEE Journal of SolidState Circuits, vol. 34, no. 4, pp. 513-519, 1999.
[3] R. B. Staszewski and P. T. Balsara, "Phase-domain all-digital phase-locked loop," IEEE Transactions on Circuits and Systems II, vol. 52, no. 3, pp. 159-163, 2005.

[4] S. Y. Lee and J. Y. Hsieh, "Analysis and implementation of a 0.9$\mathrm{V}$ voltage-controlled oscillator with low phase noise and low power dissipation," IEEE Transactions on Circuits and Systems II, vol. 55, no. 7, pp. 624-627, 2008.

[5] J. Craninckx and M. S. J. Steyaert, "1.8-GHz CMOS low-phasenoise voltage-controlled oscillator with prescaler," IEEE Journal of Solid-State Circuits, vol. 30, no. 12, pp. 1474-1482, 1995.

[6] B. Çatli and M. M. Hella, "A 0.5-V 3.6/5.2 GHz CMOS multiband LC VCO for ultra low-voltage wireless applications," in Proceedings of IEEE International Symposium on Circuits and Systems (ISCAS '08), pp. 996-999, May 2008.

[7] T. V. Cao, D. T. Wisland, T. S. Lande, and F. Moradi, "Lowvoltage, low-power, and wide-tuning-range ring-VCO for frequency $\Delta \Sigma$ modulator," in Propceedings of the 26th Norchip Conference, pp. 79-84, November 2008.

[8] L. S. De Paula, S. Bampi, E. Fabris, and A. A. Susin, "A wide band CMOS differential voltage-controlled ring oscillator," in Proceedings of the Joint IEEE North-East Workshop on Circuits and Systems and TAISA Conference (NEWCAS-TAISA '08), pp. 9-12, June 2008.

[9] M. Jamal Deen, M. H. Kazemeini, and S. Naseh, "Performance characteristics of an ultra-low power VCO," in Proceedings of 
IEEE International Symposium on Circuits and Systems, pp. 697700, May 2003.

[10] A. Hajimiri, S. Limotyrakis, and T. H. Lee, "Jitter and phase noise in ring oscillators," IEEE Journal of Solid-State Circuits, vol. 34, no. 6, pp. 790-804, 1999.

[11] T. Li, B. Ye, and J. Jiang, " $0.5 \mathrm{~V} 1.3 \mathrm{GHz}$ voltage controlled ring oscillator," in Proceedings of the 8th IEEE International Conference on ASIC (ASICON '09), pp. 1181-1184, October 2009.

[12] S. K. Enam and A. A. Abidi, " $300-\mathrm{MHz}$ CMOS voltagecontrolled ring oscillator," IEEE Journal of Solid-State Circuits, vol. 25, no. 1, pp. 312-315, 1990.

[13] B. Fahs, W. Y. Ali-Ahmad, and P. Gamand, "A two-stage ring oscillator in $0.13-\mu \mathrm{m}$ CMOS for UWB impulse radio," IEEE Transactions on Microwave Theory and Techniques, vol. 57, no. 5, pp. 1074-1082, 2009.

[14] J. K. Panigrahi and D. P. Acharya, "Performance analysis and design of wideband CMOS voltage controlled ring oscillator," in Proceedings of IEEE International Conference on Industrial and Information Systems, pp. 234-238, August2010.

[15] H. Q. Liu, W. L. Goh, and L. Siek, "A 0.18- $\mu \mathrm{m}$ 10-GHz CMOS ring oscillator for optical transceivers," in Proceedings of IEEE International Symposium on Circuits and Systems (ISCAS '05), pp. 1525-1528, May 2005.

[16] S. -Y. L. Amakawa, S. Ishihara, and N. Masu K, "Low phase noise wide frequency range ring VCO based scalable PLL with sub harmonic injection locking in $0.18 \mu \mathrm{m}$ CMOS," in Proceedings of IEEE International Microwave Symposium Digest, pp. 1178-1181, May 2010.

[17] C. H. Park and B. Kim, "A low-noise, 900-MHz VCO in 0.6- $\mu \mathrm{m}$ CMOS," IEEE Journal of Solid-State Circuits, vol. 34, no. 5, pp. 586-591, 1999.

[18] Y. A. Eken and J. P. Uyemura, "A 5.9-GHz voltage-controlled ring oscillator in 0.18- $\mu \mathrm{m}$ CMOS," IEEE Journal of Solid-State Circuits, vol. 39, no. 1, pp. 230-233, 2004.

[19] H. R. Kim, C. Y. Cha, S. M. Oh, M. S. Yang, and S. G. Lee, "A very low-power quadrature VCO with back-gate coupling," IEEE Journal of Solid-State Circuits, vol. 39, no. 6, pp. 952-955, 2004.

[20] M. Kumar, S. K. Arya, and S. Pandey, "Digitally controlled oscillator design with variable capacitance XOR gate," Journal of Semiconductor, vol. 32, no. 10, pp. 105001-105007, 2011. 

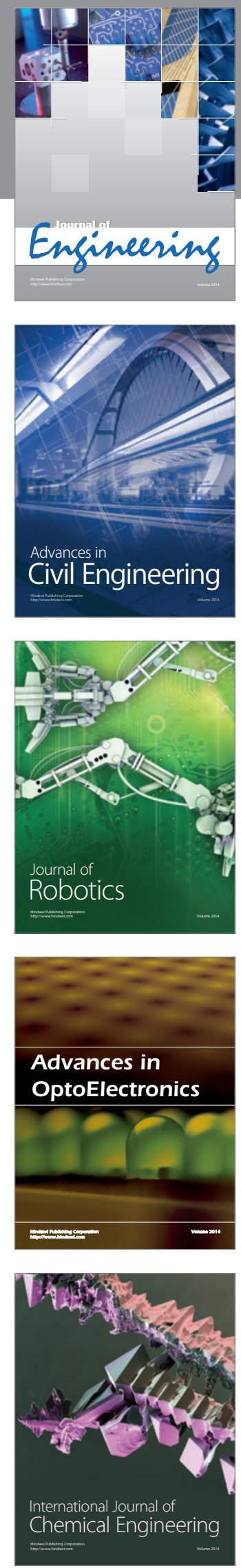

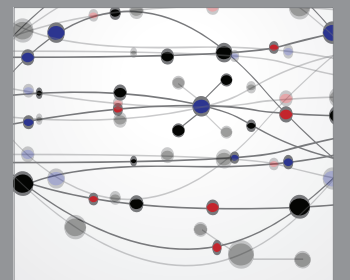

The Scientific World Journal
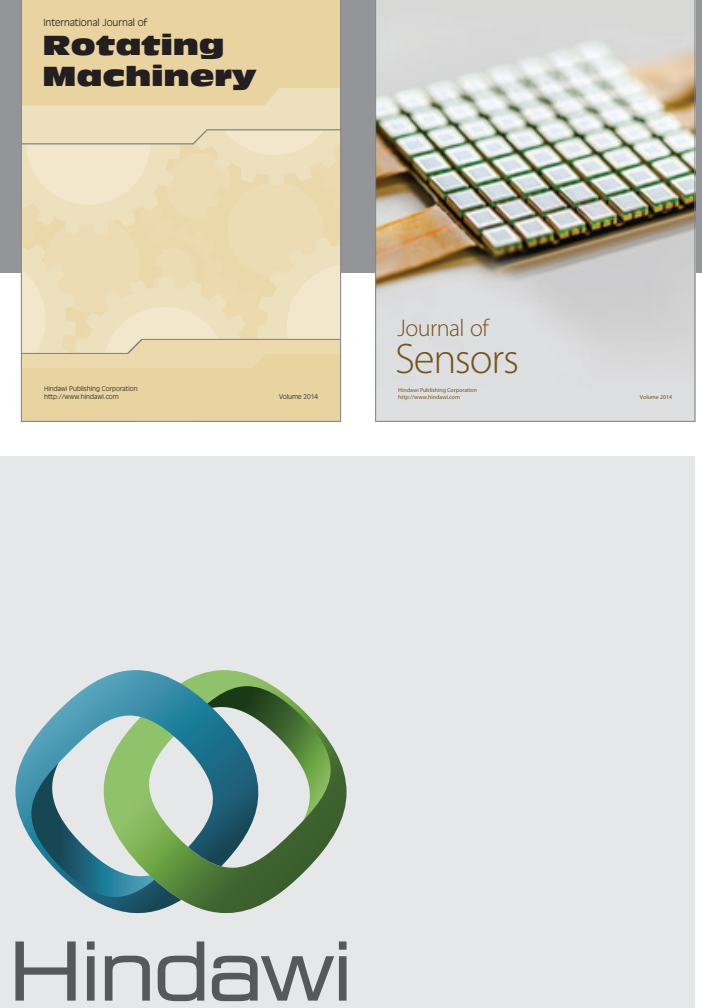

Submit your manuscripts at http://www.hindawi.com
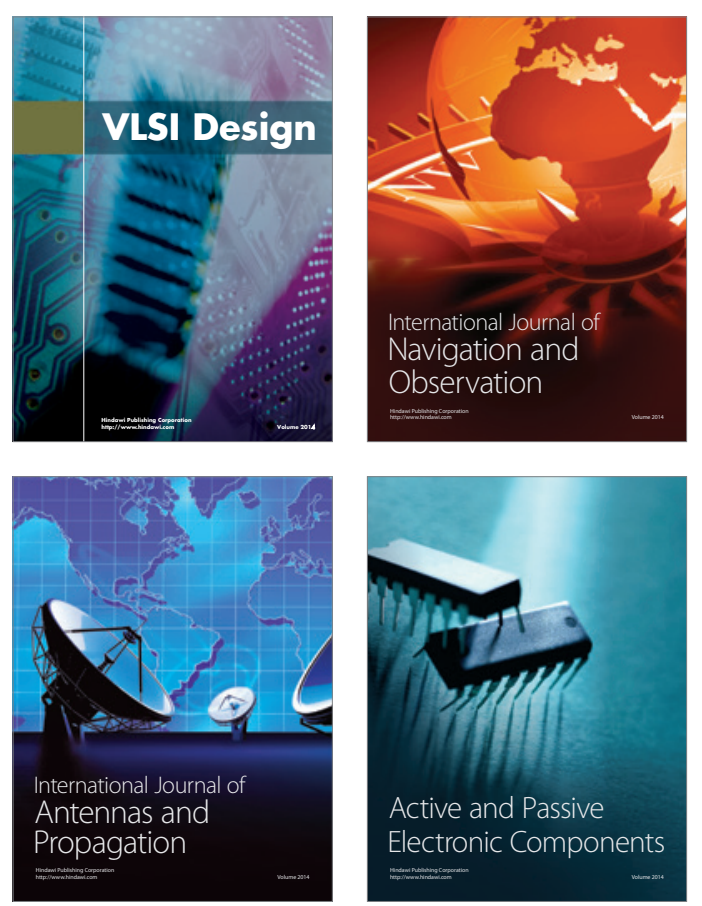
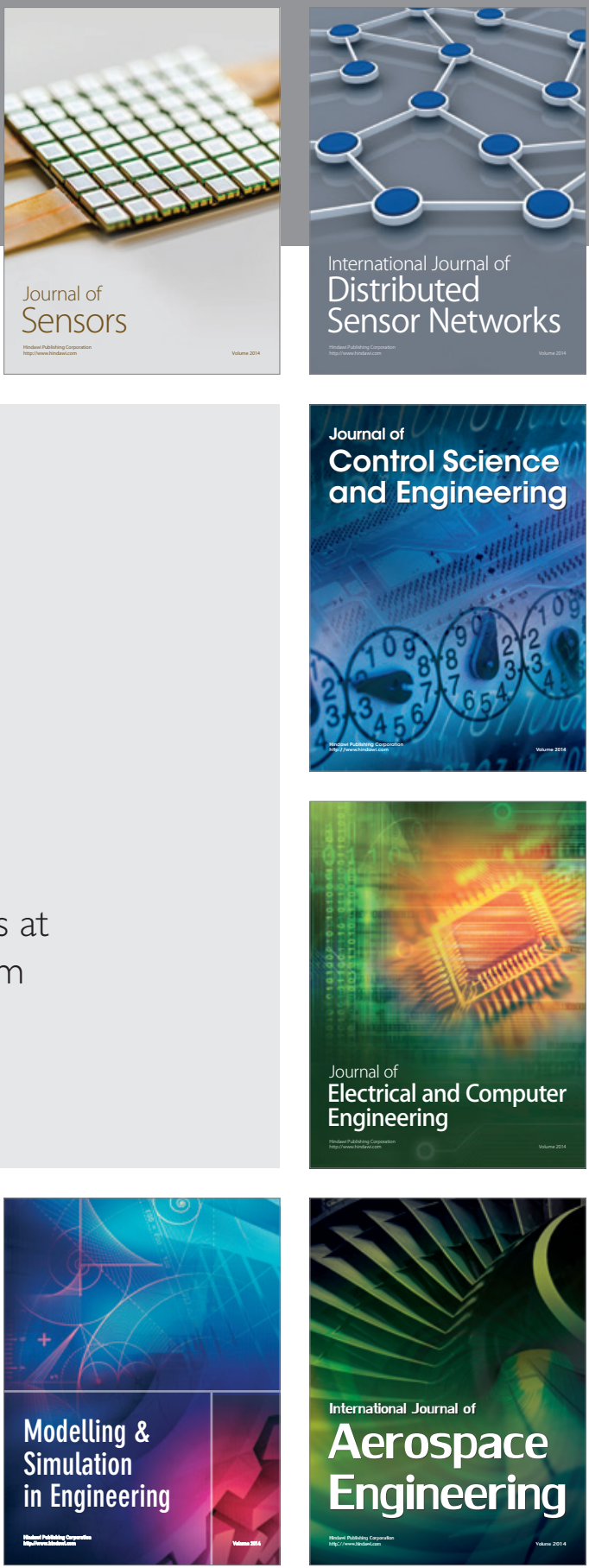

Journal of

Control Science

and Engineering
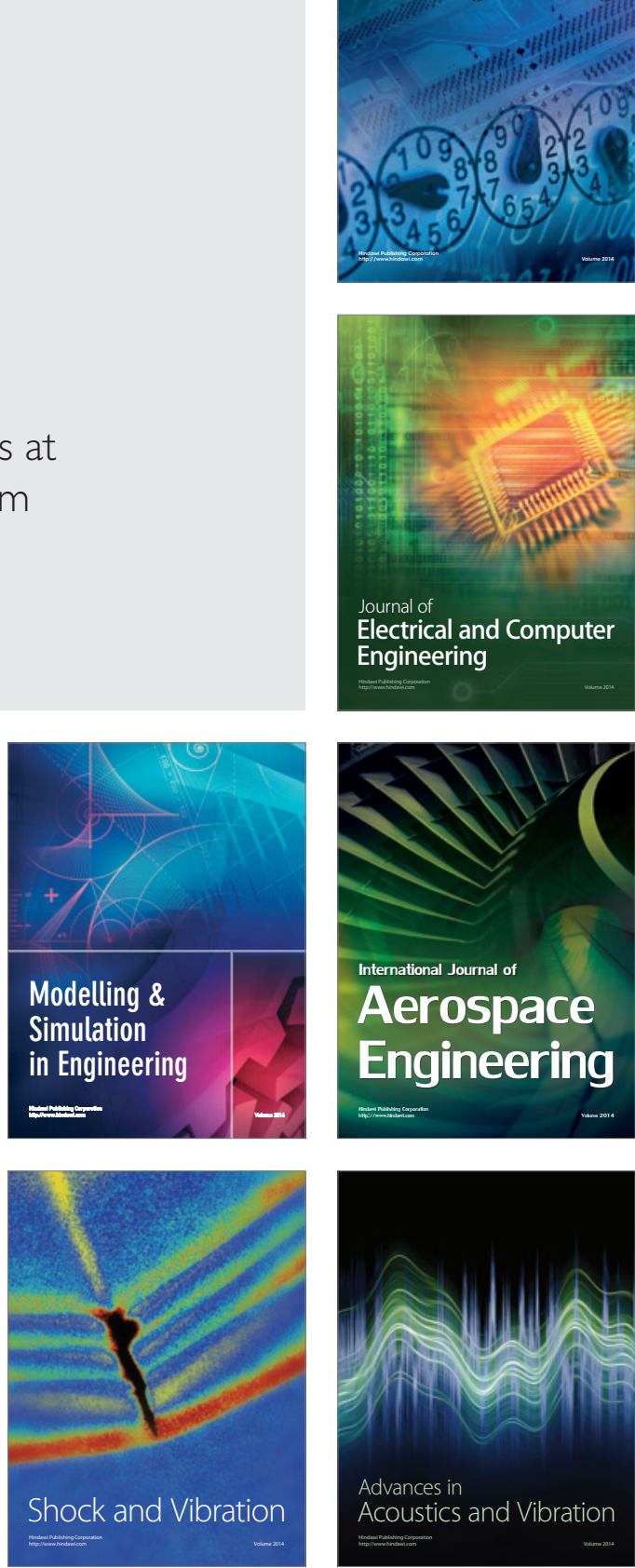